\title{
The Interaction between Stent(s) Implantation, PICA Involvement, and Immediate Occlusion Degree Affect Symptomatic Intracranial Spontaneous Vertebral Artery Dissection Aneurysm (sis-VADA) Recurrence after Reconstructive Treatment with Stent(s)-Assisted Coiling
}

\author{
Kai-Jun Zhao • Rui Zhao • Qing-Hai Huang • Yi Xu • \\ Bo Hong • Yi-Bin Fang • Qiang Li • Peng-Fei Yang • \\ Jian-Min Liu • Wen-Yuan Zhao
}

Received: 15 January 2014 /Revised: 12 March 2014 / Accepted: 7 May 2014 /Published online: 4 June 2014

(C) The Author(s) 2014. This article is published with open access at Springerlink.com

\begin{abstract}
Objectives We aimed to evaluate risk factors of sis-VADAs recurrence after reconstructive treatment based on 113 reconstructed lesions.

Methods A total of 111 patients (M:F=68:43; median age, 47 years) with 113 sis-VADAs underwent reconstruction from
\end{abstract}

Electronic supplementary material The online version of this article (doi:10.1007/s00330-014-3225-7) contains supplementary material, which is available to authorized users.

K.-J. Zhao $\cdot$ R. Zhao $\cdot$ Q.-H. Huang $\cdot$ Y. Xu $\cdot$ B. Hong $\cdot$ Y.-B. Fang $\cdot$ Q. Li $\cdot$ P.-F. Yang $\cdot$ J.-M. Liu $(\triangle) \cdot$ W.-Y. Zhao $(\triangle)$

Department of Neurosurgery, Changhai Hospital, Second Military

Medical University, Shanghai, China

e-mail: chstroke@163.com

e-mail: doczhaowy@163.com

K.-J. Zhao

e-mail: zkjwcfzwh@163.com

R. Zhao

e-mail: z_ray1979@126.com

Q.-H. Huang

e-mail: ocinhqh@163.com

$\mathrm{Y} . \mathrm{Xu}$

e-mail: xuyismmu@yahoo.com.cn

B. Hong

e-mail: hongbosmmu@hotmail.com

Y.-B. Fang

e-mail: fangyibin@vip.163.com

Q. Li

e-mail: 1qeimm@126.com

P.-F. Yang

e-mail: 15921196312@163.com
October 2000 to March 2011, using stent(s) and coils. Treatments and predictors of recurrence were retrospectively analysed.

Results Fifty-eight sis-VADAs underwent single-stent treatment, and the remaining 55 sis-VADAs underwent treatment with 2-4 overlapping stents. Follow-up angiography was available for 94 sis-VADAs $12-78$ months, with recurrence in ten patients, including seven angiographic recurrences and three post-treatment haemorrhagic recurrences. A higher rate of post-treatment recurrence was observed in the single stent group than in the multiple stents group $(p=0.010)$. The interaction between stent (s) implantation and immediate occlusion degree (odds ratio $[\mathrm{OR}]=3.152 ; 95 \%$ confidence interval [CI], 1.293-7.686; $p=0.012$ ), between stent (s) implantation and the posterior inferior cerebellar artery (PICA) involvement $(\mathrm{OR}=4.607 ; 95 \% \mathrm{CI}, 1.172-18.113 ; p=0.029)$, and between PICA involvement and immediate occlusion degree $(\mathrm{OR}=5.018 ; 95 \% \mathrm{CI}, 1.263-19.933 ; p=0.022)$ affect recurrence in the reconstructed sis-VADAs.

Conclusions This single centre cohort study indicated that the interaction effect between stent (s) implantation, PICA involvement, and immediate occlusion degree were closely associated with recurrence after reconstructive treatment of sis-VADA.

Key Points

- The interaction between stent (s) and immediate occlusion degree affect aneurysmal recurrence

- The interaction between stent and PICA involvement affect aneurysmal recurrence

- The interaction between PICA involvement and immediate occlusion degree affect aneurysmal recurrence 
Keywords Vertebral Artery Dissection · Aneurysm .

Recurrence $\cdot$ Stent $\cdot$ Coiling

\begin{tabular}{|c|c|}
\hline \multicolumn{2}{|c|}{ Abbreviations } \\
\hline \multirow{3}{*}{ sis-VADA } & Symptomatic Intracranial \\
\hline & Spontaneous Vertebral Artery \\
\hline & Dissection Aneurysm \\
\hline OR & odds ratio \\
\hline $\mathrm{CI}$ & confidence interval \\
\hline PICA & the posterior inferior cerebellar artery \\
\hline VAD & vertebral artery dissection \\
\hline SAH & subarachnoid haemorrhage \\
\hline WSS & wall shear stresses \\
\hline M & male \\
\hline $\mathrm{F}$ & female \\
\hline $\mathrm{H}-\mathrm{H}$ & Hunt-Hess \\
\hline M & month \\
\hline NA & not available \\
\hline $\mathrm{h}$ & hour \\
\hline $\mathrm{mRS}$ & modified Rankin Scale \\
\hline
\end{tabular}

\section{Introduction}

Intracranial vertebral artery dissection (VAD) has emerged as a leading cause of subarachnoid haemorrhage (SAH) and ischemic stroke of the posterior circulation, particularly in young to middle-aged adults $[1,2]$. Once the vertebral artery trunk undergoes aneurismal dilatation, a so-called dissection aneurysm forms, increasing the risk of fatal bleeding in the future [3]. Moreover, a study has indicated that the subsequent rupture $(n=14)$ rate was up to $58 \%$ in ruptured VADAs ( $n=$ 24) [4]. Hence, it is crucial to manage acute sis-VADAs in a timely manner. Endovascular treatment [5-7], including deconstructive $[6,7]$ (i.e., proximal occlusion or internal trapping) and reconstructive techniques [5, 7], has been introduced as a minimally invasive method to treat lesions in deep locations or patients at high risk for surgery-related morbidity and mortality. Among several endovascular techniques, stentrelated reconstructive treatment was shown to be better at maintaining the integrity of the PICA and the parent artery in comparison with deconstructive treatments. Moreover, the rate of post-treatment recurrence did not differ between reconstructive and deconstructive treatments [7]. However, posttreatment recurrence secondary to coil compaction and growth of the aneurysm sac remains a major shortcoming of reconstructive treatment. At present, it is still challenging to distinguish unstable aneurysm residuals from non-progressing neck remnants, which are considered to be of crucial importance in deciding which treatment option a patient should be offered.

Although a recent study indicated that involvement of PICA increased the risk of recurrence after endovascular treatment [7], nearly $51.4 \%$ (57/111) of patients in that study were not treated using reconstructive techniques. Additional measures such as the quality of stent implantation and the immediate occlusion degree are also thought to be crucial in predicting post-treatment recurrence. The aim of this study is to identify risk factors of recurrence after reconstructive treatment in a large sample of patients with sis-VADAs.

\section{Materials and methods}

The Ethics committee of the Second Military Medical University affiliated Changhai Hospital approved this retrospective study, and all written consents given by the patients were stored in the Changhai hospital database and used for research.

\section{Patients and aneurysms}

We reviewed all patients who underwent endovascular treatment for VADAs from October 2000 to March 2011 to identify patients with sis-VADAs that were reconstructed with stent(s) and coils. All subjects met the following inclusion criteria: (1) acute clinical symptoms and signs related to intracranial VADA, which was confirmed by angiography; (2) reconstruction of lesions with stent(s) and coils; and (3) at least one angiographic follow-up, except in cases of rebleeding or bleeding events after reconstructive treatment. The exclusion criteria included the following: (1) history of traumatic and iatrogenic injury; (2) lesions extending to the extracranial segment or basilar artery; (3) history of deconstructive treatment and/or sole stent(s) for sis-VADAs; (4) untreated sis-VADAs; and (5) loss to angiographic follow up, except for 3 haemorrhagic events (one re-bleeding and two haemorrhages). A total of 97 consecutive patients (M:F= 62:35; median age, 46 years; range, 27 to 80 years) with 97 sis-VADAs were identified and enrolled in this study. This series consisted of 57 (59\%) ruptured lesions and 40 (41\%) un-ruptured lesions. Clinical and radiographic characteristics, reconstructive treatment methods, and risk factors of recurrence were retrospectively analysed.

\section{Procedures}

Patients with acutely ruptured aneurysms received a loading dose of dual antiplatelet medication (300 mg clopidogrel and $300 \mathrm{mg}$ aspirin) 2 hours before the procedure, and patients with unruptured aneurysms received dual antiplatelet premedication ( $75 \mathrm{mg}$ of clopidogrel and $100 \mathrm{mg}$ of aspirin) each day for three days. All patients received systemic intravenous heparin after the femoral sheath was placed, with the goal of achieving an activated clotting time between 250 to 
300 seconds. Reconstructive treatment of the entire dissected segment was performed using coils in conjunction with either a single stent or multiple stents. A balloon-expandable coronary stent was applied in the early period, and self-expanding neurovascular stents were applied in the late period. Postprocedure, some patients $(n=61)$ were given three days of heparin (40 mg, every 12 hours, hypodermic injection), while some were not $(n=36)$. All patients were kept on a dual antiplatelet regimen for six weeks with daily clopidogrel $(75 \mathrm{mg})$ and aspirin $(100-300 \mathrm{mg})$, followed indefinitely by aspirin $(100 \mathrm{mg})$ mono-therapy.

\section{Follow-ups}

Angiographic follow up was performed using conventional angiography, which was scheduled at six months, again at 12 months, and annually thereafter. The immediate and follow-up occlusion grades were defined as complete obliteration (100\%), near-complete obliteration ( $\geqq 90 \%$, including residual dome or base), and partial obliteration $(<90 \%)[5,8$, 9]. The angiographic results were evaluated independently by two authors (Jian-Min Liu and Wen-Yuan Zhao), each with 913 years of neurointerventional experience. Angiographic recurrence was diagnosed when the contrast medium within the lesions substantially increased in comparison with a control angiogram taken immediately after treatment. Additionally, recurrence was diagnosed when haemorrhage or re-bleeding after treatment occurred in un-ruptured or ruptured sis-VADAs $[7,10]$, respectively.

\section{Statistical analysis}

Statistical analysis was performed using SPSS for Windows (SPSS17.0). An unpaired $t$ test or a Mann-Whitney $U$ test was performed for continuous variables. The $x^{2}$ test or Fisher's exact test was performed for categorical variables. The following variables were analysed: age, sex, presentation (ruptured/unruptured), involvement of the PICA origin, lesion type (dilatation without stenosis or dilatation with stenosis), blood supply to the basilar artery, stent(s) implantation (single stent or multiple stents), immediate occlusion degree, and usage of post-procedural heparin. Univariate analysis were performed to determine the association of post-treatment recurrence with other factors. Logistic regression analysis was performed to determine the independent association of posttreatment recurrence with other factors. The univariate analysis cut-off for inclusion in the logistic regression analysis was $p<0.20$. When variables were not independent predictors of recurrence, the interaction between the variables was also determined. A $p<0.05$ for a $95 \%$ CI was considered statistically significant.

\section{Results}

Treatment

Stent implantation was defined as a successful placement if the deployed single stent or overlapped multiple ones in a telescopic fashion extended at least $5 \mathrm{~mm}$ over aneurysmal neck (lateral protrusion-shaped dissection aneurysms) or the border of other dissection lesions (i.e., fusiform-shaped, et al.) on both sides of the target vessel [8]. All inclusion VADAs were successfully reconstructed with coiling combined with either a single stent $(n=50 ; 31$ ruptured, 19 unruptured) or multiple stents ( $n=47 ; 26$ ruptured, 21 unruptured). Six patients suffered from adverse events, including one re-bleeding (Case 7) and two bleeding (Case 10,11) (Table 1). One patient was initially treated with triple stents and coils for a ruptured lesion involving the PICA, resulting in immediate PICA occlusion, which might be attributed to coil migration to the origin of the PICA, SAH or both. Two patients (one ruptured, one unruptured) were treated with two or three overlapping stents and coils but died of subsequent ischemic events (one severe cerebral vasospasm-Case 8 , one cerebral stem infarction- Case 9). The remaining three patients (one ruptured-Case 7, two unruptured- Case 10,11) underwent reconstructive treatment with one stent $(n=2)$ or two overlapping stents, which achieved partial obliteration, but they subsequently died due to haemorrhage $(n=2)$ or re-bleeding $(n=1)$ 24-48 hours after treatment. Therefore, the periprocedural complication rate was $6 \%$ among the 97 sisVADA repairs. Additionally, two patients (one ruptured, one unruptured) were reconstructed with 1-2 stent(s) and coiling, which achieved partial obliteration, but they subsequently died of the suspected haemorrhage event in six months (Case 7) or 26 months (Case 14) after treatment, respectively. The overall mortality rate was $7 \%(7 / 97)$, but the haemorrhage- or re-bleeding-related mortality was $3 \%$ (3/97). All surviving patients were clinically followed for a mean of 58 months (range, 12132 months). Clinical outcomes were unfavourable (modified Rankin Scale score, 2-6) in 6 of 40 unruptured VADA patients and in 10 of 57 ruptured VADA patients.

Angiographic results

Angiographic follow up was available for 94 sis-VADA patients 12-78 months (mean, 23 months) after treatment. This series included three patients with posttreatment haemorrhagic recurrence, one of whom initially presented with a ruptured lesion and two of whom presented with un-ruptured lesions. Tables 2 and 3 
Table 1 Data of 10 Recurrences (7 Angiographic, 1 re-bleeding, and 2 bleeding) and 7 deaths

\begin{tabular}{|c|c|c|c|c|c|c|c|c|c|}
\hline Case & Age/Sex & Rup-ture & $\mathrm{H}-\mathrm{H}$ & PICA-Involving & Stent (s) & Obliteration & Heparin & $\begin{array}{l}\text { Angiographic Recurrence } \\
\text { (Intervials) }\end{array}$ & $\begin{array}{l}\text { Clinical Outcome } \\
\text { mRS (Intervials) }\end{array}$ \\
\hline 1 & $48 / \mathrm{M}$ & Yes & 2 & Yes & Balloon-expandable & Partial & Yes & Yes $(12 \mathrm{M})$ & $0(110 \mathrm{M})$ \\
\hline 2 & $27 / \mathrm{F}$ & Yes & 2 & Yes & Neuroform & Partial & Yes & Yes $(10 \mathrm{M})$ & $0(78 \mathrm{M})$ \\
\hline 3 & $42 / \mathrm{M}$ & Yes & 2 & Proximal & LEO & Partial & Yes & Yes $(3 \mathrm{M})$ & $0(40 \mathrm{M})$ \\
\hline 4 & 49/M & Yes & 2 & Yes & Enterprise & Partial & Yes & Yes $(6 \mathrm{M})$ & $0(7 \mathrm{M})$ \\
\hline 5 & $35 / \mathrm{M}$ & Yes & 2 & Yes & Enterprise & Partial & Yes & Yes $(7 \mathrm{M})$ & $1(27 \mathrm{M})$ \\
\hline 6 & $44 / F$ & Yes & 1 & Yes & LEO & Partial & Yes & No (Suspected re-bleeding) & $\begin{array}{l}6(6 \mathrm{M}) \\
\quad \text { Sudden death }\end{array}$ \\
\hline 7 & $65 / \mathrm{M}$ & Yes & 1 & Yes & Enterprise & Partial & Yes & No (Re-bleeding) & $6(48$ h) (death) \\
\hline 8 & $54 / \mathrm{M}$ & Yes & 4 & distal & 3 Enterprise & Complete & Yes & NA & $6(48 \mathrm{~h})$ death \\
\hline 9 & $52 / \mathrm{F}$ & No & l & distal & 2 Neuroform & Partial & No & $\begin{array}{l}\text { Complete obliteration } \\
\text { (14 M) }\end{array}$ & $6(21 \mathrm{M})$ death \\
\hline 10 & $47 / F$ & No & l & Yes & 2 Solitaire & Partial & Yes & Bleeding (24 h) & $6(24$ h) (death) \\
\hline 11 & $58 / \mathrm{F}$ & No & l & distal & Enterprise & Partial & Yes & Bleeding (/) & $6(48$ h) (death) \\
\hline 12 & $60 / \mathrm{M}$ & No & l & distal & Neuroform & Partial & Yes & Yes $(8 \mathrm{M})$ & $0(72 \mathrm{M})$ \\
\hline 13 & $34 / \mathrm{M}$ & No & l & Yes & 3 Enterprise & Complete & No & Yes $(6 \mathrm{M})$ & $0(40 \mathrm{M})$ \\
\hline 14 & $39 / \mathrm{M}$ & No & l & Yes & 2 Leo & Partial & Yes & No (Suspected re-bleeding) & $\begin{array}{l}6(26 \mathrm{M}) \\
\text { Sudden death }\end{array}$ \\
\hline
\end{tabular}

M, male; F, female; H-H, Hunt-Hess; PICA, the posterior inferior cerebellar artery; M, month; NA, no available; h, hour; mRS, modified Rankin Scale

summarize the characteristics of the treated sis-VADAs and risk factors of post-treatment recurrence on univariate analysis, respectively. Although treatment type was not associated with differences between the group with lesions involving the PICA and the group with lesions not involving the PICA $(p=0.230$, Table 2$)$ or between patients with ruptured lesions and those with unruptured lesions ( $p=0.504$, Table 2), multiple stents had the clear preponderance over a single stent in increasing the immediate angiographic occlusion degree $(p=0.011$, Table 2). Of the 97 reconstructed lesions, there were ten recurrences (seven angiographic recurrences, one rebleeding, two haemorrhages), which were more frequently observed in the group with lesions involving the PICA $(18 \%$ vs. $5 \%$ in the group with lesions not involving the PICA, $p=0.042$, Table 3 ), in the
Table 2 Data on the initial treatment of 97 sis-VADAs

sis-VADA $=$ symptomatic intracranial spontaneous vertebral artery dissection aneurysm

\begin{tabular}{|c|c|c|c|c|}
\hline Variables & Single stent $(n=50)$ & Multiple stents $(n=47)$ & Total $(n=97)$ & $p$ Value \\
\hline \multicolumn{4}{|l|}{ Sex, n $(\%)$} & \multirow[t]{3}{*}{0.660} \\
\hline Male & $33(53)$ & $29(47)$ & 62 & \\
\hline Female & $17(49)$ & $18(51)$ & 35 & \\
\hline \multicolumn{4}{|l|}{ Presentation, $\mathrm{n}(\%)$} & \multirow[t]{3}{*}{0.504} \\
\hline Ruptured & $31(54)$ & $26(46)$ & 57 & \\
\hline Un-ruptured & $19(48)$ & $21(52)$ & 40 & \\
\hline \multicolumn{4}{|l|}{ PICA Involvement } & \multirow[t]{3}{*}{0.230} \\
\hline Yes & $23(59)$ & $16(41)$ & 39 & \\
\hline No & $27(47)$ & $31(53)$ & 58 & \\
\hline \multicolumn{4}{|l|}{ Aneurysmal Type, n (\%) } & \multirow[t]{3}{*}{0.163} \\
\hline Dilatation without stenosis & $26(46)$ & $31(54)$ & 57 & \\
\hline Dilatation with stenosis & $24(60)$ & $16(40)$ & 40 & \\
\hline \multicolumn{4}{|c|}{ Blood Supply to Basilar Artery, n (\%) } & \multirow[t]{3}{*}{0.076} \\
\hline Predominant & $15(68)$ & $7(32)$ & 22 & \\
\hline Equal & $35(47)$ & $40(53)$ & 75 & \\
\hline \multicolumn{4}{|c|}{ Immediate Angiographic Occlusion Results, n (\%) } & \multirow[t]{4}{*}{0.011} \\
\hline Complete Obliteration & $7(27)$ & $19(73)$ & 26 & \\
\hline Near-complete Obliteration & $11(55)$ & $9(45)$ & 20 & \\
\hline Partial Obliteration & $32(63)$ & $19(37)$ & 51 & \\
\hline
\end{tabular}


Table 3 Predictors of sis-VADA Recurrence after Reconstruction by univariate analysis

\begin{tabular}{|c|c|c|c|c|}
\hline Variables & Yes $(n=10)$ & No $(n=87)$ & Total $(n=97)$ & $p$ Value \\
\hline Age, $\mathrm{y}$, Mean \pm SD & $45.70 \pm 12.49$ & $49.53 \pm 10.37$ & & 0.354 \\
\hline \multicolumn{5}{|l|}{ Sex, n $(\%)$} \\
\hline Male & $8(13)$ & $54(87)$ & 62 & \multirow[t]{2}{*}{0.263} \\
\hline Female & $2(6)$ & $33(94)$ & 35 & \\
\hline \multicolumn{5}{|l|}{ Presentation, $\mathrm{n}(\%)$} \\
\hline Ruptured & $6(11)$ & $51(89)$ & 57 & \multirow[t]{2}{*}{0.933} \\
\hline Un-ruptured & $4(10)$ & $36(90)$ & 40 & \\
\hline \multicolumn{4}{|l|}{ PICA Involvement, $\mathrm{n}(\%) *$} & \multirow[t]{3}{*}{0.042} \\
\hline Yes & $7(18)$ & $32(82)$ & 39 & \\
\hline No & $3(5)$ & $55(95)$ & 58 & \\
\hline \multicolumn{4}{|l|}{ Aneurysmal Type, n (\%) } & \multirow[t]{3}{*}{0.446} \\
\hline Dilatation without stenosis & $7(12)$ & $50(88)$ & 57 & \\
\hline Dilatation with stenosis & $3(8)$ & $37(92)$ & 40 & \\
\hline \multicolumn{4}{|l|}{ Blood Supply to Basilar Artery } & \multirow[t]{3}{*}{0.559} \\
\hline Predominant & $3(14)$ & $19(86)$ & 22 & \\
\hline Equal & $7(9)$ & $68(91)$ & 75 & \\
\hline \multicolumn{4}{|l|}{ Stent(s) Implantation, $\mathrm{n}(\%) *$} & \multirow[t]{3}{*}{0.010} \\
\hline Single stent + coils & $9(18)$ & $41(82)$ & 50 & \\
\hline Multiple stents + coils & $1(2)$ & $46(98)$ & 47 & \\
\hline \multicolumn{4}{|c|}{ Immediate Occlusion Degree, no $(\%) *$} & \multirow[t]{4}{*}{0.040} \\
\hline Complete obliteration & $1(4)$ & $25(96)$ & 26 & \\
\hline Near-complete obliteration & $0(0)$ & $20(100)$ & 20 & \\
\hline Partial obliteration & $9(18)$ & $42(82)$ & 51 & \\
\hline \multicolumn{4}{|l|}{ Usage of Post-procedural Heparin } & \multirow[t]{3}{*}{0.237} \\
\hline Yes & $8(13)$ & $53(87)$ & 61 & \\
\hline No & $2(6)$ & $34(94)$ & 36 & \\
\hline
\end{tabular}

single-stent group (18\% vs. $2 \%$ in the multiple-stent group, $p=0.010$, Table 3 ), and in the partial obliteration group (18\% vs. $4 \%$ in the complete obliteration group, $p=0.040$, Table 3).

The rate of post-treatment recurrence did not differ between patients with ruptured sis-VADAs and those with unruptured sis-VADAs $(p=0.933$, Table 3$)$, nor in patients with or without post-procedural heparin for three days. Of the ten recurrences, $90 \%$ (9/10, including one haemorrhage and one re-bleeding) occurred in lesions with partial obliteration after a single stent, $60 \%$ (6/10, including one haemorrhage and one rebleeding) occurred in lesions involving the PICA with partial obliteration after treatment, and $50 \%(5 / 10$, including one re-bleeding) occurred in lesions involving the PICA that were reconstructed using a single stent. Logistic regression analysis indicated that the interaction between stent (s) implantation and immediate occlusion degree (odds ratio[OR] $=3.152 ; 95 \%$ confidence interval [CI], 1.293-7.686; $p=0.012$, on-line Table 4), between stent (s) implantation and PICA involvement $(\mathrm{OR}=$ $4.607 ; 95 \%$ CI, 1.172-18.113; $p=0.029$, on-line Table 5), and between PICA involvement and immediate occlusion degree $(\mathrm{OR}=5.018 ; 95 \% \mathrm{CI}, 1.263$ -
19.933; $p=0.022$, on-line Table 6) were closely associated with the reconstructed sis-VADAs recurrence.

\section{Discussion}

The instability of coils remains the primary shortcoming of endovascular treatment. Thus, it is necessary to identify patients who will require further treatment. The data published thus far on post-treatment recurrence primarily pertain to saccular aneurysms, and few studies have focused on intracranial VADAs recurrence. Due to differences in aetiology, anatomic configuration, and treatment method, the saccular aneurysm-related predictors of recurrence, such as aneurysm size [11-13], width of the neck [13, 14], treatment during the acute phase after aneurysm rupture [12-14], initially suboptimal angiographic aneurysm occlusion [12-14], and length of follow up [13, 14] could not accurately be applied to sisVADAs. Recently, our study based on 57 ruptured dissection aneurysms indicated partial obliteration following singlestent-assisted coiling had higher risk of recurrence and rebleeding [15]. Hence, the interaction between the variables may play a crucial role in the recurrence of reconstructed sisVADAs. An in-depth investigation facilitated the early 

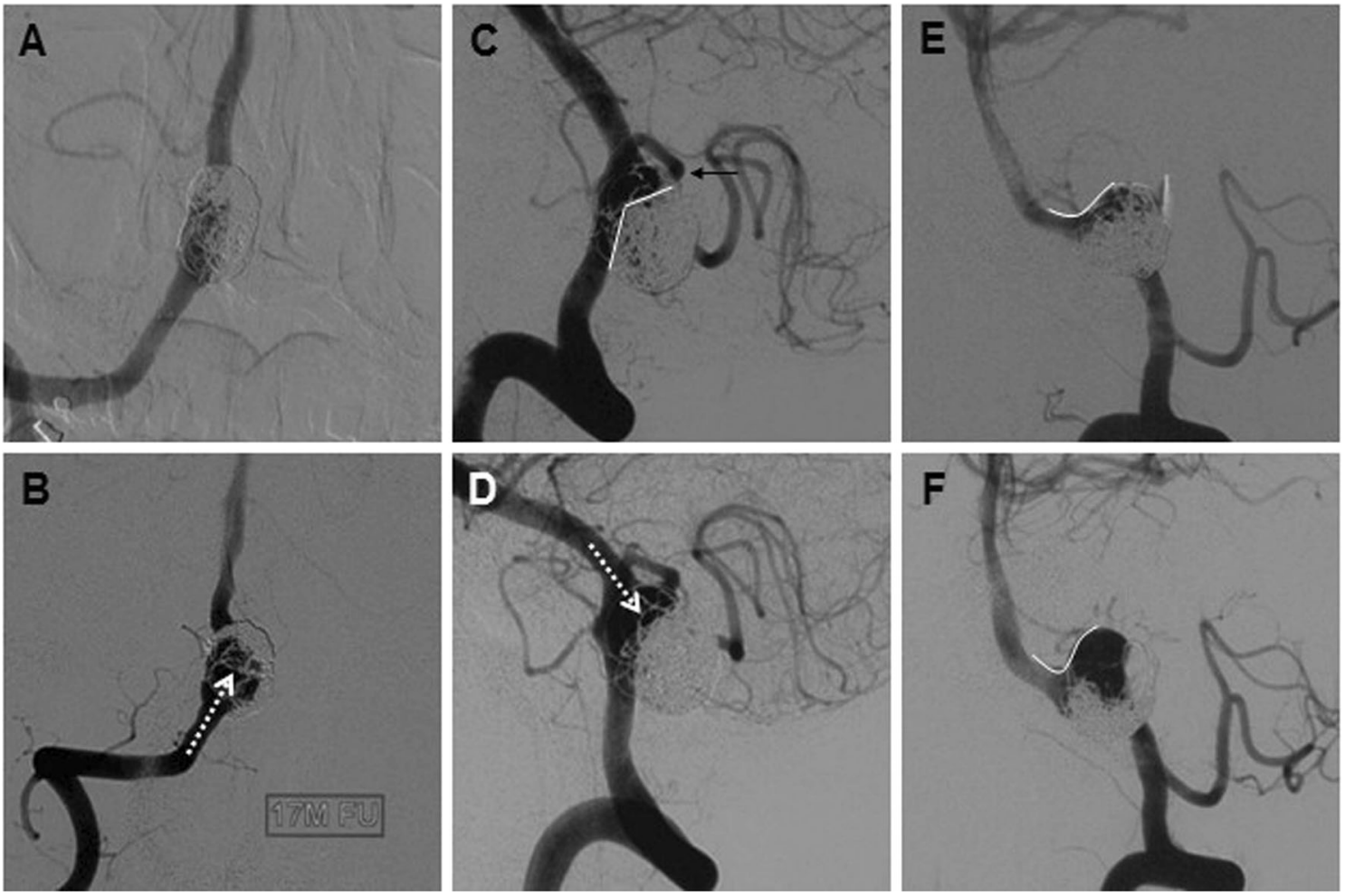

Fig. 1 Recurrent sis-VADAs reconstructed using a single stent and coiling. (A-B) A partially occluded VADA, not involving the PICA, recurred due to antegrade coil compaction (white arrow) at 8 months (A) and 1.5 years (B) after single-stent reconstruction. (C-D) A VADA involving the PICA (C, black arrow) was partially occluded (C),

occurring retrograde (white arrow) coil compaction (D) 3 months after single-stent reconstruction. (E-F) A partially occluded VADA (E) involving aneurysm sac occurred growth and coil compaction (F) 10 months after single-stent treatment

recognition of risk factors of post-treatment recurrence, leading to more prompt treatment. This study focused on sisVADA-related post-treatment recurrence and its predictors. To our knowledge, this study is the first to evaluate predictors of recurrence after reconstructive treatment of sis-VADAs.

Generally, the recurrence and rupture of the reconstructed VADAs were a continuous course. Post-treatment recurrence attributed to antegrade (Fig. 1B) or retrograde (Fig. 1D) coil mass compaction, sac growth (Fig. 1F) or a new dissection formation (Fig. 2B), and a high wall shear stresses (WSS) within the recanalization zone may play critical roles in recurrence [16]. Table 3 indicates that lesions involving the PICA, single-stent reconstructions, and partial obliteration were risk factors for post-treatment recurrence by univariate analysis. However, none of these variables was an independent predictor of recurrence by logistic regression analysis. This finding was inconsistent with a previous study in which PICA involvement was the only independent risk factor for recurrence after the endovascular treatment of vertebrobasilar dissecting aneurysms [7]. These differences could be attributed to differences in treatment method.

Irrespective of PICA involvement, the interaction effect between stent(s) implantation and immediate occlusion degree was significantly related to post-treatment recurrence (on-line Table 4). Our results demonstrated that nine ( $90 \%$, including

one haemorrhage and one re-bleeding) of the ten recurrences occurred in lesions with partial obliteration after treatment with a single stent (Fig. 1). Even if the PICA was not involved, this risk remained high (Fig. 1A-1B). By contrast, only one ( $2 \%)$ of the 47 lesions treated with multiple stents recurred at six months (Fig. 2A-2C) after treatment. On the one hand, overlapping multiple stents were better than single stents in decreasing intra-aneurismal WSS [17-19] which prevented coil compaction and aneurismal rupture and growth. On the other hand, treatment with a single stent led to a higher rate of immediate partial obliteration in comparison with treatment with multiple stents $(p=0.011$, Table 2$)$, which was also a risk factor for post-treatment recurrence (Table 3). Previous studies have indicated that the degree of aneurysm occlusion after initial treatment is a strong predictor of the risk of subsequent rupture in patients presenting with subarachnoid haemorrhage [20]. Hence, provided that a lesion is not completely occluded, the use of overlapping multiple stents with lower stent porosity may be an alternative for preventing recurrence or haemorrhagic events, as was also well-documented in flowdiverter devices [21, 22].

The interaction effect between stent(s) implantation and PICA involvement was significantly associated with posttreatment recurrence (on-line Table 5). Our results showed that five (50\%, including one re-bleeding) of the ten 

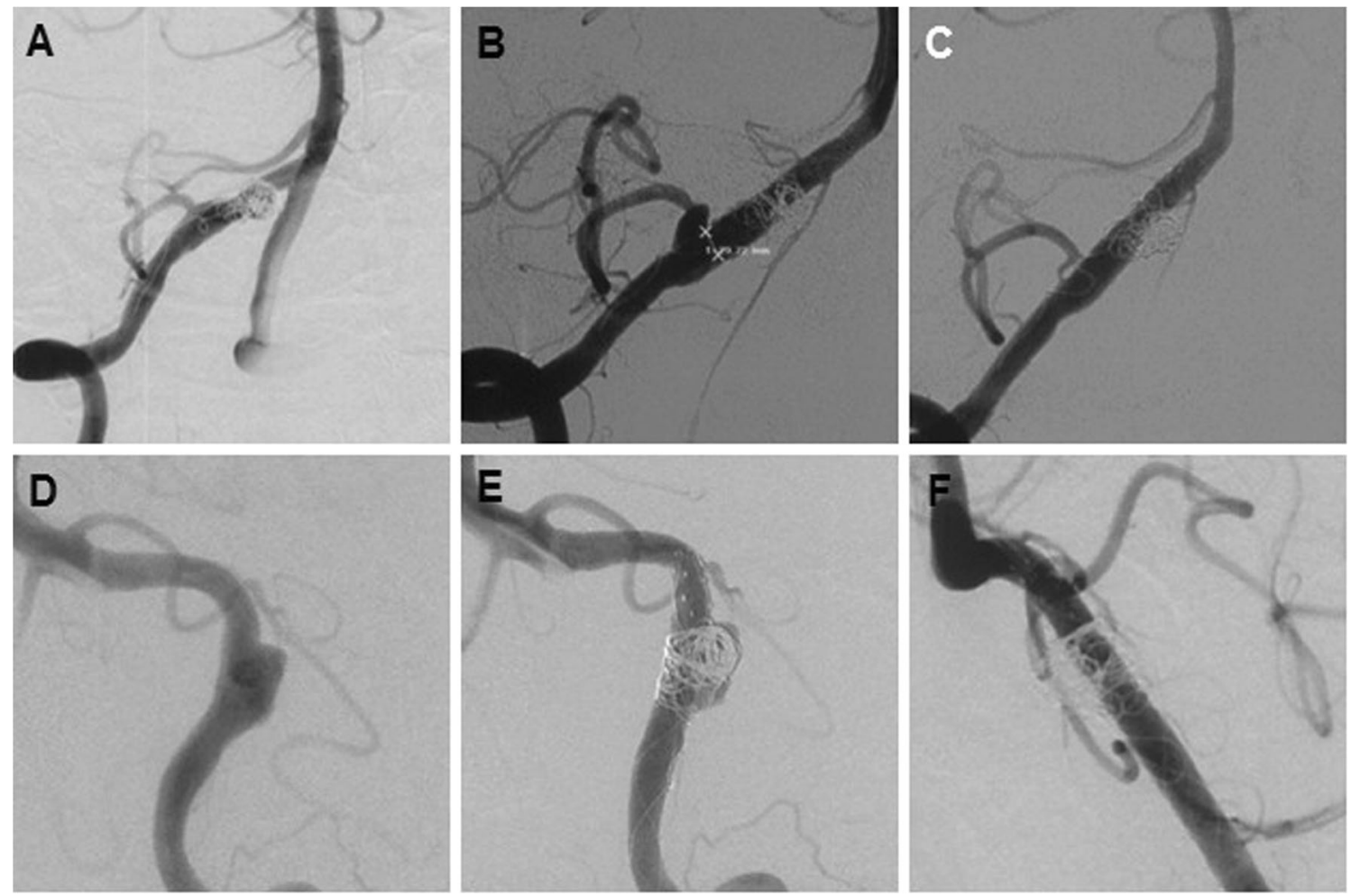

Fig. 2 sis-VADAs reconstructed with multiple stents and coiling. (A-C) A VADA involving the PICA was reconstructed with three Enterprise stents (A). After 6 months, a recurrence was observed at the origin of the PICA (B) and was effectively retreated with an additional Solitaire AB

stent and followed up for 6 months (C). (D-F) A VADA (D) was reconstructed with four overlapping stents, and immediate partial obliteration was achieved (E). An 8-month follow-up angiogram showed normalization $(\mathrm{F})$

recurrences occurred in lesions involving the PICA that were reconstructed using single stent (Fig. 1C-1D); these lesions had the same hemodynamic status as saccular lesions with partial obliteration after single-stent reconstructive treatment. When lesions involving the PICA were reconstructed by a stent, a small portion of the dissecting aneurysm sac was left, which allowed continuous antegrade or retrograde blood flow into the PICA (Fig. 1C), increasing the risk of recurrence (Fig. 1D). Several studies have indicated that aneurysm rerupture [20] and angiographic recurrence [23-25] are closely related to incomplete aneurysm occlusion. Although stentassociated flow remodeling could cause further occlusion of incompletely coiled aneurysms [26], intracranial dissecting aneurysms $(18 \%, 7 / 39$, Table 3$)$ recur at a higher rate than do saccular aneurysms $(8.3 \%-14 \%[27,28])$ during follow up when a single stent and coiling was employed. A possible explanation for this difference is the greater fragility of the wall of a dissecting aneurysm than of the wall of a Berry aneurysm. Another possible explanation may be the differing aetiology and more complicated anatomic configurations [29], such as intramural hematomas, pearl-and-string configurations, and intimal flap configurations. Because aneurysm recanalizations are located in high-WSS areas [16], the use of multiple stents helps prevent recurrence and haemorrhagic events due to greater reductions in WSS $[17,18]$. In our series
(Fig. 2A-2 F,), only two $(4 \%, 2 / 47)$ patients whose lesions were reconstructed using multiple stents suffered a recurrence $(n=1)$ or haemorrhagic event $(n=1)$.

Regardless of whether treatment involved a single stent (Fig. 1C-1D) or multiple stents (Fig. 2A-2B), the interaction effect between PICA involvement and immediate occlusion degree was closely associated with posttreatment recurrence (on-line Table 6). Our results showed that $60 \%$ of the recurrences (6/10, including two haemorrhages) occurred in patients with lesions involving the PICA that were partially obliterated after treatment. Even if partial obliteration was achieved in patients with multiple stents, the post-treatment recurrence risk remained high (Fig. 2A-2B). Although the lesions did not recur in the obliterated region (Fig. 2A-2B), new aneurysms originated from the PICA, which suggested that aneurysm sac growth [30] (Fig. 1E-1 F) may be the recurrence mechanism. Initial PICA involvement with the VADA was closely associated with post-treatment recurrence and rebleeding in intracranial VADAs [7, 31]. In this series, one patient with a ruptured lesion and one patient with an unruptured lesion that were repaired with single stent experienced haemorrhagic events, including one re-bleeding and one haemorrhage. It is possible that low WSS at end-diastole caused degeneration and thinning of the aneurysm wall and 
that high pressure at peak systole resulted in rupture of the thinning wall [32]. Another underlying mechanism may be related to unfavourable hemodynamic changes (i.e., the outflow being restricted more than the inflow) after reconstructive treatment [33], autolysis of the aneurysm wall secondary to thrombus [34], or both.

Although the outcomes of single stent-assisted coiling for intracranial saccular aneurysms are encouraging [27, 28] single-stent reconstructive treatment of sis-VADAs involves a high risk of recurrence, particularly in lesions involving the PICA and lesions with immediate partial obliteration. In the future, flow-diverter devices, such as the pipeline [21] and silk [22] devices, may be a promising choice for preventing recurrence.

This study suffered from several limitations, including the retrospective design, patient selection bias, and limited number of cases. Additionally, one ruptured and one unruptured lesion resulted in re-bleeding and haemorrhage within 48 hours after initial treatment, respectively. The recurrence and rupture of lesions were continuous in the disease course, and autolysis of the aneurysm secondary to thrombosis formation after treatment may be a cause of delayed aneurysm rupture [35]. Hence, it is reasonable to assume that recurrent VADAs caused the observed haemorrhage or re-bleeding.

In conclusion, this single centre cohort indicated that the interaction between stent(s) implantation and immediate occlusion degree, between stent(s) implantation and PICA involvement, and between PICA involvement and immediate occlusion degree were closely associated with recurrence in the reconstructed sis-VADAs, and multiple stents had the clear preponderance over single stent in preventing recurrence. However, multiple stents seemed be affected by worse morbidity, mortality and outcome based on the result that five of six patients with adverse events received multiple stents treatment. Further study is required to verify these findings.

\begin{abstract}
Acknowledgements The scientific guarantor of this publication is JianMin Liu. The authors of this manuscript declare relationships with the following companies: The authors of this manuscript declare no relationships with any companies, whose products or services may be related to the subject matter of the article. This study has received funding by the National Natural Science Foundation of China (grant No. 81171093, 81000495, 81271271, 30973102, and 81101906). Kai-Jun Zhao kindly provided statistical advice for this manuscript. Kai-Jun Zhao, one of the authors, has significant statistical expertise. No complex statistical methods were necessary for this paper. Institutional Review Board approval was obtained. Written informed consent was obtained from all subjects (patients) in this study. This study is not on animals. Some study subjects or cohorts have been previously reported in Plos One (Reconstructive Treatment of Ruptured Intracranial Spontaneous Vertebral Artery Dissection Aneurysms: Long-Term Results and Predictors of Unfavorable Outcomes. PLoS One. 2013;8(6): e67169. doi:10.1371/journal. pone.0067169). Methodology: retrospective, observational, performed at one institution.
\end{abstract}

Kai-Jun Zhao and Rui Zhao contributed equally to this work.
Open Access This article is distributed under the terms of the Creative Commons Attribution Noncommercial License which permits any noncommercial use, distribution, and reproduction in any medium, provided the original author(s) and the source are credited.

\section{References}

1. Mizutani T, Aruga T, Kirino T et al (1995) Recurrent subarachnoid hemorrhage from untreated ruptured vertebrobasilar dissecting aneurysms. Neurosurgery 36:905-911, discussion 912-903

2. Arnold M, Bousser MG, Fahrni G et al (2006) Vertebral artery dissection: presenting findings and predictors of outcome. Stroke J Cereb Circ 37:2499-2503

3. Ro A, Kageyama N, Abe N et al (2009) Intracranial vertebral artery dissection resulting in fatal subarachnoid hemorrhage: clinical and histopathological investigations from a medicolegal perspective. J Neurosurg 110:948-954

4. Kurata A, Ohmomo T, Miyasaka Y et al (2001) Coil embolization for the treatment of ruptured dissecting vertebral aneurysms. Am J Neuroradiol 22:11-18

5. Suh SH, Kim BM, Park SI et al (2009) Stent-assisted coil embolization followed by a stent-within-a-stent technique for ruptured dissecting aneurysms of the intracranial vertebrobasilar artery. Clinical article. J Neurosurg 111:48-52

6. Leibowitz R, Do HM, Marcellus ML et al (2003) Parent vessel occlusion for vertebrobasilar fusiform and dissecting aneurysms. Am J Neuroradiol 24:902-907

7. Kim BM, Shin YS, Kim SH et al (2011) Incidence and risk factors of recurrence after endovascular treatment of intracranial vertebrobasilar dissecting aneurysms. Stroke J Cereb Circ 42:2425-2430

8. Zhao KJ, Zhang YW, Xu Y et al (2013) Reconstruction of saccular and dissected intracranial aneurysms using solitaire ab stents. PLoS One 8:e57253

9. Wakhloo AK, Mandell J, Gounis MJ et al (2008) Stent-assisted reconstructive endovascular repair of cranial fusiform atherosclerotic and dissecting aneurysms: long-term clinical and angiographic follow-up. Stroke J Cereb Circ 39:3288-3296

10. Ono H, Nakatomi H, Tsutsumi K et al (2013) Symptomatic recurrence of intracranial arterial dissections: follow-up study of 143 consecutive cases and pathological investigation. Stroke J Cereb Circ 44:126-131

11. Ferns SP, Sprengers ME, van Rooij WJ et al (2009) Coiling of intracranial aneurysms: a systematic review on initial occlusion and reopening and retreatment rates. Stroke J Cereb Circ 40:e523-e529

12. Campi A, Ramzi N, Molyneux AJ et al (2007) Retreatment of ruptured cerebral aneurysms in patients randomized by coiling or clipping in the international subarachnoid aneurysm trial (isat). Stroke J Cereb Circ 38:1538-1544

13. Sluzewski M, van Rooij WJ, Rinkel GJ et al (2003) Endovascular treatment of ruptured intracranial aneurysms with detachable coils: long-term clinical and serial angiographic results. Radiology 227: 720-724

14. O'Kelly C, Macdonald RL (2008) Coiling and aneurysm rerupture: incomplete treatment is a causal intermediate not a confounder. Stroke J Cereb Circ 39:e121, author reply e122

15. Zhao KJ, Fang YB, Huang QH et al (2013) Reconstructive treatment of ruptured intracranial spontaneous vertebral artery dissection aneurysms: long-term results and predictors of unfavorable outcomes. PLoS One 8:e67169

16. Luo B, Yang X, Wang S et al (2011) High shear stress and flow velocity in partially occluded aneurysms prone to recanalization. Stroke J Cereb Circ 42:745-753 
17. Lieber BB, Stancampiano AP, Wakhloo AK (1997) Alteration of hemodynamics in aneurysm models by stenting: influence of stent porosity. Ann Biomed Eng 25:460-469

18. Kim M, Levy EI, Meng H et al (2007) Quantification of hemodynamic changes induced by virtual placement of multiple stents across a wide-necked basilar trunk aneurysm. Neurosurgery 61:1305-1312, discussion 1312-1303

19. Meng H, Wang Z, Kim M et al (2006) Saccular aneurysms on straight and curved vessels are subject to different hemodynamics: implications of intravascular stenting. Am J Neuroradiol 27:1861-1865

20. Johnston SC, Dowd CF, Higashida RT et al (2008) Predictors of rehemorrhage after treatment of ruptured intracranial aneurysms: the cerebral aneurysm rerupture after treatment (carat) study. Stroke J Cereb Circ 39:120-125

21. Saatci I, Yavuz K, Ozer C et al (2012) Treatment of intracranial aneurysms using the pipeline flow-diverter embolization device: a single-center experience with long-term follow-up results. Am J Neuroradiol 33:1436-1446

22. Lubicz B, Collignon L, Raphaeli G et al (2010) Flow-diverter stent for the endovascular treatment of intracranial aneurysms: a prospective study in 29 patients with 34 aneurysms. Stroke J Cereb Circ 41: 2247-2253

23. Raymond J, Guilbert F, Weill A et al (2003) Long-term angiographic recurrences after selective endovascular treatment of aneurysms with detachable coils. Stroke J Cereb Circ 34: 1398-1403

24. Nguyen TN, Hoh BL, Amin-Hanjani S et al (2007) Comparison of ruptured vs unruptured aneurysms in recanalization after coil embolization. Surg Neurol 68:19-23

25. Grunwald IQ, Papanagiotou P, Struffert T et al (2007) Recanalization after endovascular treatment of intracerebral aneurysms. Neuroradiology 49:41-47
26. Lawson MF, Newman WC, Chi YY et al (2011) Stent-associated flow remodeling causes further occlusion of incompletely coiled aneurysms. Neurosurgery 69:598-603, discussion 603-594

27. Fargen KM, Hoh BL, Welch BG et al (2012) Long-term results of enterprise stent-assisted coiling of cerebral aneurysms. Neurosurgery 71:239-244, discussion 244

28. Santillan A, Greenberg E, Patsalides A et al (2012) Long-term clinical and angiographic results of neuroform stent-assisted coil embolization in wide-necked intracranial aneurysms. Neurosurgery 70:1232-1237, discussion 1237

29. Ahn SS, Kim BM, Suh SH et al (2012) Spontaneous symptomatic intracranial vertebrobasilar dissection: initial and follow-up imaging findings. Radiology 264:196-202

30. Hasan DM, Nadareyshvili AI, Hoppe AL et al (2012) Cerebral aneurysm sac growth as the etiology of recurrence after successful coil embolization. Stroke J Cereb Circ 43:866-868

31. Takagi T, Takayasu M, Suzuki Y et al (2007) Prediction of rebleeding from angiographic features in vertebral artery dissecting aneurysms. Neurosurg Rev 30:32-38, discussion 38-39

32. Kono K, Fujimoto T, Shintani A et al (2012) Hemodynamic characteristics at the rupture site of cerebral aneurysms: a case study. Neurosurgery 71:E1202-E1208, discussion 1209

33. Cebral JR, Mut F, Raschi M et al (2011) Aneurysm rupture following treatment with flow-diverting stents: computational hemodynamics analysis of treatment. Am J Neuroradiol 32:27-33

34. Turowski B, Macht S, Kulcsar Z et al (2011) Early fatal hemorrhage after endovascular cerebral aneurysm treatment with a flow diverter (silk-stent): do we need to rethink our concepts? Neuroradiology 53: $37-41$

35. Kulcsar Z, Houdart E, Bonafe A et al (2011) Intra-aneurysmal thrombosis as a possible cause of delayed aneurysm rupture after flow-diversion treatment. Am J Neuroradiol 32:20-25 